\title{
KAJIAN KONDISI FISIK TERMINAL LEUWIPANJANG BERDASARKAN PERSEPSI PENUMPANG
}

\author{
Tiafahmi Angestiwi \\ Prodi Manajemen Aset, Jurusan Administrasi Niaga Politeknik Negeri Bandung \\ Penulis Korespondensi e-mail : tia.fahmi@polban.ac.id
}

\begin{abstract}
Leuwipanjang terminal is a passenger terminal serving AKDP and AKAP. UPTD Terminal is required to provide convenient facilities for passengers during activities within the Terminal. Physically, terminal facilities cover two important aspects of maintenance and availability of terminal facilities. Therefore, to know the physical performance of the terminal, conducted a review of the results of maintenance and service. This study aims to determine the perception of passengers on the maintenance results by UPTD Terminal and Terminal physical facilities services. The research method used is descriptive research method. While the data collection techniques used include observation and questionnaires. Analysis of data processing using descriptive analysis and theoretical comparison analysis. From the result of research, it can be concluded that the study of maintenance activity is considered not good. While the study of terminal services is considered quite good. In this regard, it is necessary to improve the quality of cleanliness and the quality of the room, as well as to review the terminal services by creating safety, security, reliability and regularity, convenience, convenience or affordability, and equity.
\end{abstract}

Key Word: Passenger terminal, physical condition of the building, maintenance activities, terminal services

\begin{abstract}
ABSTRAK
Terminal Leuwipanjang merupakan terminal penumpang yang melayani AKDP dan AKAP. UPTD Terminal dituntut untuk menyediakan sarana yang nyaman untuk penumpang selama berkegiatan di dalam Terminal. Secara fisik, sarana terminal mencakup dua aspek penting yakni hasil pemeliharaan dan ketersediaan fasilitas terminal. Oleh karena itu untuk mengetahui kinerja fisik terminal, dilakukan kajian terhadap hasil pemeliharaan dan pelayanan. Penelitian ini bertujuan untuk mengetahui persepsi penumpang terhadap hasil pemeliharaan oleh UPTD Terminal dan pelayanan fasilitas fisik Terminal. Metode penelitian yang digunakan yakni metode penelitian deskriptif. Sedangkan teknik pengumpulan data yang digunakan antara lain observasi dan kuesioner. Analisis pengolahan data menggunakan analisis deskriptif dan analisis perbandingan secara teoritis. Dari hasil penelitian, dapat disimpulkan bahwa kajian terhadap kegiatan pemeliharaan dinilai kurang baik. Sedangkan kajian terhadap pelayanan terminal dinilai cukup baik. Sehubungan dengan hal tersebut, perlu dilakukan peningkatan kualitas kebersihan dan mutu ruangan, serta upaya mengkaji pelayanan terminal dengan menciptakan keselamatan, keamanan, keandalan dan keteraturan, kenyamanan, kemudahan atau keterjangkauan, serta kesetaraan.

Kata Kunci: Terminal penumpang, kondisi fisik bangunan gedung, kegiata pemeliharaan, pelayanan terminal
\end{abstract}




\section{PENDAHULUAN}

Bandung merupakan salah satu kota yang mengalami perkembangan yang cepat di berbagai aspek. Perkembangan tersebut merupakan proses interaksi dan akumulasi dari berbagai sistem aktivitas sehingga memperkuat percepatan perkembangan Kota Bandung. Perannya sebagai pusat kota industri, perniagaan, pariwisata, dan pendidikan membutuhkan akses serta mobilitas yang semakin tinggi jika dilihat dari hubungannya dengan wilayah luar maupun terhadap bagian di dalam kota. Hal tersebut mengakibatkan perlunya pengelolaan elemen transportasi yang memadai. Salah satunya adalah terminal yang memindahkan penumpang dari satu tempat ke tempat lainnya.

Menurut Blow (2005) terminal perlu didesain nyaman dan memiliki daya tarik namun cenderung sederhana. Desain terminal harus dapat mendukung fungsi utamanya sebagai tempat pemberangkatan, pemberhentian atau pemindahan penumpang dengan memanfaatkan ruang tunggu. Tingginya manfaat terminal harus ditunjang dengan kemudahan dalam hal pencapaian khususnya bagi penumpang. Sebagai sebuah icon pemberi kesan psikologis, terminal juga dapat dijadikan sebagai tempat berkumpul yang nyaman dan aman oleh para penggunanya.

Salah satu terminal yang memberikan icon bagi pendatangnya dari luar kawasan kota Bandung yaitu Terminal Leuwipanjang. Terminal Leuwipanjang merupakan terminal penumpang yang melayani pergerakan Antar Kota Antar Provinsi (AKAP) dan Antar Kota Dalam Provinsi (AKDP). Terminal Leuwipanjang memiliki dua kategori Angkutan Umum Penumpang (AUP) yakni rute angkutan dan rute bus damri. Menurut Abubakar (1996) fungsi terminal penumpang dapat ditinjau dari tiga unsur utama yakni bagi penumpang, pemerintah, dan operator atau pengusaha angkutan. Bagi penumpang, terminal dapat memberikan kenyamanan saat menunggu, kenyamanan perpindahan dari satu moda atau kendaraan ke moda lain, tempat fasilitas-fasilitas informasi, dan fasilitas parkir kendaraan pribadi.

Berdasarkan Angestiwi (2013) persentase pengguna AUP meliputi pelajar, pegawai, bisnis, dan lain-lain. Lebih jelasnya dapat dilihat pada Gambar 1 tentang persentase pengguna terminal berdasarkan profesi. Dapat diamati bahwa pengguna terbanyak yaitu penumpang dengan profesi pegawai sebesar 52\%. Kemudian 26\% pelajar, paling jarang yakni pengguna dengan profesi bisnis sekitar 4\%. Pengguna AUP di dalam kota tidak hanya berasal dari dalam 
Kota Bandung, namun juga berasal dari kota-kota sekitar yaitu, Bogor, Bekasi, Soreang, Cianjur, dan Jakarta.

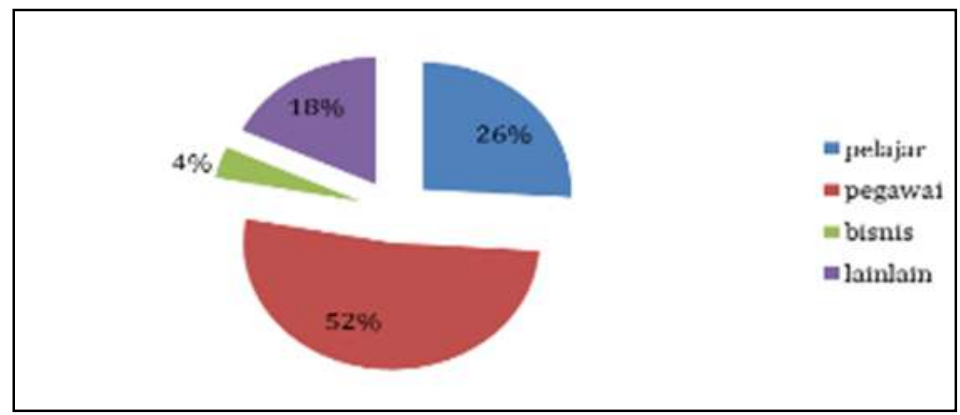

Gambar 1 Persentase Pengguna AUP Berdasarkan Profesi Sumber: Angestiwi, 2013

Berdasarkan fenomena di lapangan memperlihatkan kondisi dimana penumpang AUP belum memanfaatkan terminal sebagai tempat memulai, mengakhiri, bahkan berganti dari satu moda transportasi ke transportasi lainnya. Dari segi lokasi, terminal Leuwipanjang berada pada on street sehingga para penumpang dapat menjangkaunya dengan mudah. Berdasarkan pemberitaan Tahun 2016 di repbulika.co.id tercatat adanya tindak kejahatan pada wanita di Terminal Penumpang Leuwipanjang. Para penumpang justru merasa kurang nyaman saat berada di terminal sehingga lebih memilih menunggu di pinggiran jalan maupun trotoar di luar kawasan terminal.

Kondisi tersebut dapat diartikan bahwa penumpang Terminal Leuwipanjang tidak memperoleh keamanan dan kenyamanan dalam berlalu lintas di kawasan terminal. Dalam Undang-undang Nomor 28 Tahun 2002 dikatakan bahwa keamanan merupakan keadaan terbebasnya setiap orang, barang, atau kendaraan dari gangguan perbuatan melawan hukum atau rasa takut dalam berlalu lintas. Salah satu aspek yang dapat mewujudkan rasa aman terhadap seluruh pengguna terminal yakni dengan tersedianya informasi maupun fasilitas yang mampu mencegah segala tindakan melawan hukum.

Kinerja fisik merupakan indikator yang menggambarkan ketersediaan fasilitas suatu bangunan gedung. Kinerja fisik tersebut berkaitan dengan kinerja bangunan, pemeliharaan, dan daya tahan bangunan (Seshadhri, 2017). Upaya yang dapat dilakukan untuk mengetahui kondisi fisik terminal penumpang Leuwipanjang yakni melalui peninjauan fisik oleh pihak pengelola dan penumpang sebagai stakeholder. Dari sisi pemerintah khususnya Dinas Perhubungan Kota Bandung, fungsi terminal sebagai prasarana transportasi sudah memadai. 
Berdasarkan Angestiwi (2013) kinerja terminal Leuwipanjang sudah dapat mendukung pergerakan di Kota Bandung yakni kegiatan ekonomi, sosial, dan kebudayaan. Sehingga dapat dikatakan bahwa keberadaan terminal mampu memberikan manfaat bagi Kota Bandung

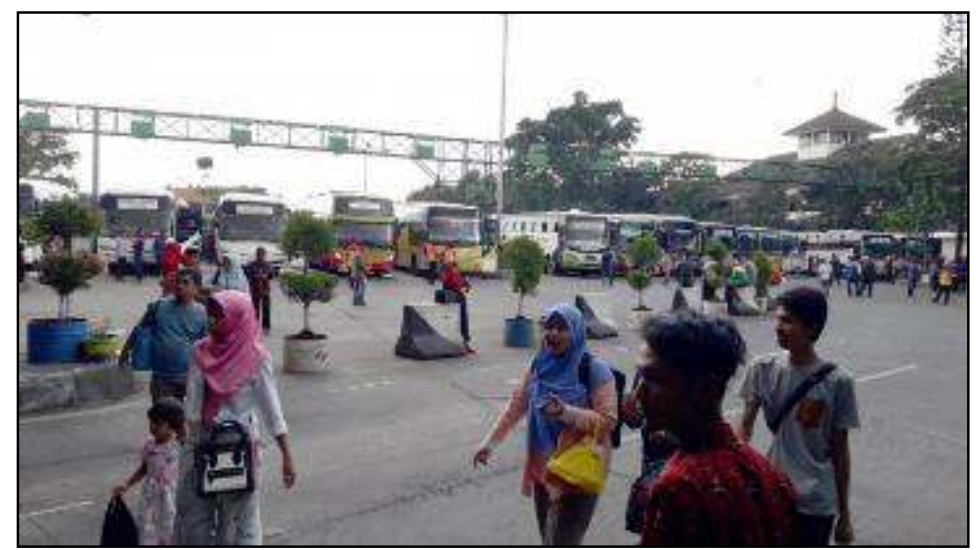

Gambar 2. Kegiatan Penumpang di Kawasan Terminal Leuwipanjang Kota Bandung Sumber: hasil dokumentasi peneliti, 2017

Bagi penumpang terminal Leuwipanjang bukan hanya membantu akvititas perpindahan ke tempat lain namun juga untuk dapat beraktivitas secara aman di kawasan tersebut. Menurut Undang-undang No.2 Tahun 2009 tentang lalu lintas dan angkutan jalan, penumpang adalah orang yang berada di kendaraan selain pengemudi dan awak kendaraan. Penumpang memberikan persepsi selama berkegiatan di kawasan terminal. Persepsi tersebut diperoleh berdasarkan pengamatan ataupun penalaran terhadap kondisi fisik terminal yang secara menyeluruh memberikan pengaruh terhadap fisik maupun psikologis (Harvey dan Swith, 1997).

Berdasarkan kondisi tersebut, permasalahan yang akan diatasi berdasarkan analisis situasi latar belakang yakni bagaimana persepsi penumpang terhadap hasil pemeliharaan aspek kondisi fisik terminal penumpang Leuwipanjang dan bagaimana persepsi penumpang terhadap pelayanan fasilitas fisik terminal penumpang Leuwipanjang?

\section{METODOLOGI}

Populasi dalam penelitian ini adalah seluruh penumpang yang menggunakan terminal Leuwipanjang sebagai tempat memulai dan mengakhiri perjalanan. Jenis populasi yang digunakan yakni populasi infinit, yakni anggota populasi yang memiliki kecenderungan bertambah maupun berkurang. Teknik sampling yang digunakan yakni accidental sampling. 
Menurut Sugiama (2008) accidental sampling adalah pengambilan sampel menurut pertimbangan subjektif peneliti bersangkutan, baik manyangkut ukuran sampel maupun penunjukkan individu anggota sampel dari anggota populasi bersangkutan. Peneliti memilih responden yang terdekat dengannya, atau yang pertama kali dijumpainya.

Teknik pengumpulan data yang digunakan yakni teknik pengumpulan data primer dan data sekunder. Data primer dibutuhkan untuk menjelaskan persepsi penumpang yang menggunakan terminal sebagai tempat berhenti dan memulai AUP. Data primer diperoleh melalui kuesioner dan observasi non perilaku. Sedangkan data sekunder diperoleh dari UPTD Terminal dan Dinas Perhubungan Kota Bandung. Data tersebut berupa fasilitas utama serta fasilitas pendukung Terminal Leuwipanjang. Variabel yang digunakan untuk mengkaji kondisi fisik terminal Leuwipanjang berdasarkan Persepsi Penumpang (Hariyono, 2007) meliputi kegiatan pemeliharaan dan pelayanan terminal. Adapun operasionalisasi variabel kondisi fisik terminal Leuwipanjang, dapat dilihat pada Tabel 1.

Tabel 1. Operasionalisasi Variabel Kondisi Fisik Terminal Leuwipanjang

\begin{tabular}{|c|c|c|c|}
\hline Variabel & Sub Variabel & Indikator & Pernyataan \\
\hline 1 & 2 & 3 & 4 \\
\hline \multirow{19}{*}{$\begin{array}{l}\text { Kondisi Fisik } \\
\text { adalah keadaan } \\
\text { maupun } \\
\text { persyaratan } \\
\text { yang harus } \\
\text { dipenuhi secara } \\
\text { fisik suatu aset } \\
\text { (Hariyono, } \\
\text { 2007) }\end{array}$} & \multirow{13}{*}{$\begin{array}{l}\text { 1. Pemeliharaan } \\
\text { adalah kegiatan } \\
\text { menjaga } \\
\text { keandalan } \\
\text { bangunan gedung } \\
\text { beserta prasarana } \\
\text { dan sarananya } \\
\text { agar bangunan } \\
\text { gedung selalu laik } \\
\text { fungsi (Permen } \\
\text { PU No.24 Tahun } \\
\text { 2008 tentang } \\
\text { Pedoman } \\
\text { Pemeliharaan dan } \\
\text { Perawatan } \\
\text { Bangunan } \\
\text { Gedung) }\end{array}$} & Plafon & Plafon bebas dari kotor, tidak ada sarang laba-laba \\
\hline & & Kaca & Kaca tidak ada kotoran \\
\hline & & Lantai & $\begin{array}{l}\text { Lantai bersih, tidak berdebu, tidak bernoda, tidak } \\
\text { buram, tidak basah, tidak bau, nat lantai bersih }\end{array}$ \\
\hline & & Ruang toilet & Ruang toilet tidak bau \\
\hline & & Kaca cermin & Kaca cermin toilet benit, terang, tidak kusam \\
\hline & & Kloset & $\begin{array}{l}\text { Klosed mengalir lancar, tidak ada noda, tidak ada } \\
\text { bercak air di sekelilingnya }\end{array}$ \\
\hline & & Kran & Kran tidak berkarat, basah, dan kusam \\
\hline & & Lantai toilet & $\begin{array}{l}\text { Lantai toilet bersih, kering, tidak ada noda, tidak } \\
\text { ada sampah }\end{array}$ \\
\hline & & Keset & $\begin{array}{l}\text { Keset tidak berdebu, tidak basah, tidak ada sampah, } \\
\text { tidak bau }\end{array}$ \\
\hline & & Taman & Taman subur, bersih, rapi, indah \\
\hline & & Lantai aspal & $\begin{array}{l}\text { Lantai aspal bersih, tidak ada sampah, tidak banjir, } \\
\text { tidak kotor tanah }\end{array}$ \\
\hline & & Tata udara dalam & Tata udara di lorong terminal tidak sumpek \\
\hline & & Tata udara luar & Tata udara di ruang luar tidak sumpek \\
\hline & \multirow{6}{*}{$\begin{array}{l}\text { 2. Pelayanan atau } \\
\text { pelayanan publik } \\
\text { adalah kegiatan } \\
\text { atau rangkaian } \\
\text { kegiatan dalam } \\
\text { rangka pemenuhan }\end{array}$} & \multirow[t]{6}{*}{ Keselamatan } & Tersedia lajur pejalan kaki \\
\hline & & & Tersedia fasilitas keselamatan jalan \\
\hline & & & Tersedia jalur evakuasi \\
\hline & & & Tersedia alat pemadam kebakaran \\
\hline & & & Tersedia pos dan fasilitas kesehatan \\
\hline & & & Tersedia informasi fasilitas keselamata, petunjuk \\
\hline
\end{tabular}


Jurnal Planologi Vol. 15, No. 1, April 2018

Available: http://jurnal.unissula.ac.id/index.php/psa

\begin{tabular}{|c|c|c|c|c|}
\hline Variabel & \multirow{9}{*}{\multicolumn{2}{|c|}{\begin{tabular}{l|}
\multicolumn{1}{|c|}{ Sub Variabel } \\
kebutuhan \\
pelayanan sesuai \\
dengan peraturan \\
perundang- \\
undangan bagi \\
setiap warga \\
Negara dan \\
penduduk atas \\
barang, jasa, dan \\
atau pelayanan \\
administrasi yang \\
disediakan oleh \\
penyelenggara \\
pelayanan publik
\end{tabular}}} & Indikator & $\begin{array}{l}\text { Pernyataan } \\
\end{array}$ \\
\hline & & & & jalur evakuasi dan titik kumpul yang mudah terlihat \\
\hline & & & & $\begin{array}{l}\text { Tersedia informasi fasilitas kesehatan yang mudah } \\
\text { terlihat dengan jelas }\end{array}$ \\
\hline & & & \multirow[t]{3}{*}{ Keamanan } & $\begin{array}{l}\text { Tersedia pos keamanan, kamera pengawas dan titik } \\
\text { pengamanan tertentu }\end{array}$ \\
\hline & & & & $\begin{array}{l}\text { Tersedia papan informasi pengaduan pada tempat } \\
\text { yang strategis }\end{array}$ \\
\hline & & & & $\begin{array}{l}\text { Tersedia jadwal kedatangan dan keberangkatan } \\
\text { serta besaran tarid kendaraan bermotor secara } \\
\text { tertulis }\end{array}$ \\
\hline & & & \multirow[t]{3}{*}{$\begin{array}{l}\text { Keandalan dan } \\
\text { keteraturan }\end{array}$} & $\begin{array}{l}\text { Tersedia jadwal kendaraan umum dalam trayek } \\
\text { lanjutan }\end{array}$ \\
\hline & & & & Tersedia loket penjualan tiket tetap dan teratur \\
\hline & & & & Tersedia kantor penyelenggara terminal \\
\hline & & (Peraturan Menteri & \multirow[t]{12}{*}{ Kenyamanan } & Tersedia ruang tunggu \\
\hline & & Perhubungan $\mathrm{Rl}$ & & Kondisi area tidak berbau \\
\hline & & No.40 Tahun 2015 & & Jumlah toilet 2 urinoir, 2 WC, 2 wastafel \\
\hline & & tentang Standar & & Tersedia fasilitas ibadah kapasitas 5-7 orang \\
\hline & & Pelayanan & & Luasan toilet pria untuk 7 orang \\
\hline & & $\begin{array}{l}\text { Penyelenggaraan } \\
\text { Terminal }\end{array}$ & & Tersedia RTH \\
\hline & & Penumnano & & Tersedia fasilitas rumah makan sesuai kebutuhan \\
\hline & & Angkutan Jalan). & & Tersedia fasilitas dan petugas kebersihan \\
\hline & & Standar pelayanan & & Tersedia tempat istirahat awak kendaraan \\
\hline & & vang waib & & Tersedia area merokok \\
\hline & & disediakan dan & & Tersedia drainase yang memadai \\
\hline & & dilaksanakan oleh & & Tersedia lampu penerangan yang memadai \\
\hline & & penylenggara: & \multirow{8}{*}{$\begin{array}{l}\text { Kemudahan/keterj } \\
\text { angkauan }\end{array}$} & Letak jalur pemberangkatan tetap dan teratur \\
\hline & \multirow{9}{*}{\multicolumn{2}{|c|}{$\begin{array}{l}\text { 1) Kesehatan } \\
\text { 2) Keamanan } \\
\text { 3) Kehandalan } \\
\text { 4) Kenyamanan } \\
\text { 5) Kemudahan } \\
\text { 6) Kesetaraan }\end{array}$}} & & $\begin{array}{l}\text { Jalur pemberangkatan terpisah dengan jalur } \\
\text { penurunan penumpang }\end{array}$ \\
\hline & & & & Letak jalur kedatangan tetap dan teratur \\
\hline & & & & $\begin{array}{l}\text { Jalur kedatangan terpisah dengan jalur penurunan } \\
\text { penumpang }\end{array}$ \\
\hline & & & & Tersedia tempat penitipan barang \\
\hline & & & & Tersedia fasilitas pengisian baterai \\
\hline & & & & Aksesibilitas tinggi platform sama dengan lantai bus \\
\hline & & & & Tersedia tempat parkir memadai \\
\hline & & & \multirow[t]{2}{*}{ Kesetaraan } & Aksesibilitas toilet bagi pengguna disable \\
\hline & & & & Tersedia ruang ibu menyusui \\
\hline
\end{tabular}

Sumber: Hariyono, 2007

\section{PEMBAHASAN DAN HASIL}

Terminal Leuwipanjang merupakan terminal penumpang yang sudah dioperasikan kurang lebih 22 tahun. Terminal Leuwipanjang dikelola oleh Dinas Perhubungan Kota Bandung melalui Unit Pelayanan Teknik Dinas (UPTD) Terminal. Terminal Leuwipanjang berlokasi di jalan Soekarno Hatta No.205 Kelurahan Situ Saeur Kecamatan Bojongloa Kidul Kota Bandung. Kawasan tersebut merupakan padat aktivitas dibidang perdagangan dan jasa. 
Disamping itu kawasan Terminal Leuwipanjang juga terdapat pemukiman kelas menengah ke bawah.

\section{Persepsi Penumpang Terhadap Hasil Pemeliharaan Aspek Kondisi Fisik Terminal Penumpang Leuwipanjang}

Pemeliharaan adalah kegiatan menjaga keandalan bangunan gedung beserta prasarana dan sarananya agar bangunan gedung selalu laik fungsi (Peraturan Menteri Pekerjaan Umum No.24 Tahun 2008 tentang Pedoman Pemeliharaan dan Perawatan Bangunan Gedung). Dalam mendukung upaya pemeliharaan tersebut ada dua tolak ukur yakni standar tingkat kebersihan dan mutu ruangannya. Dalam menentukan tingkat kebersihan suatu ruangan digunakan standar

yang lazim untuk menentukan kebersihan plafon, kaca, lantai, toilet, taman dan jalan. Sedangkan mutu ruangan adalah kemampuan maupun kinerja dari suatu ruangan untuk memenuhi kebutuhan pelanggan sebagai stakeholder (Heizer dan Render, 2004).

Standar kebersihan dan mutu ruangan terminal Leuwipanjang berdasarkan persepsi penumpangdinilai cukup baik. Elemen standar kebersihan yang menjadi tolak ukur yakni plafon, kaca cermin, kran, keset toilet, taman, lantai aspal, udara lorong, dan udara luar ruangan. Kondisi plafon di lorong luar dekat tempat tunggu penumpang terlihat berdebu, kusam, berbekas bocoran air dan ada sarang laba-laba di sudut-sudutnya. Sedangkan kondisi kaca berdebu, nampak buram dan frame kaca kurang terawat.

Tiafahmi Angestiwi I 55 Kajian Kondisi Fisik Terminal Leuwipanjang... 
Jurnal Planologi Vol. 15, No. 1, April 2018

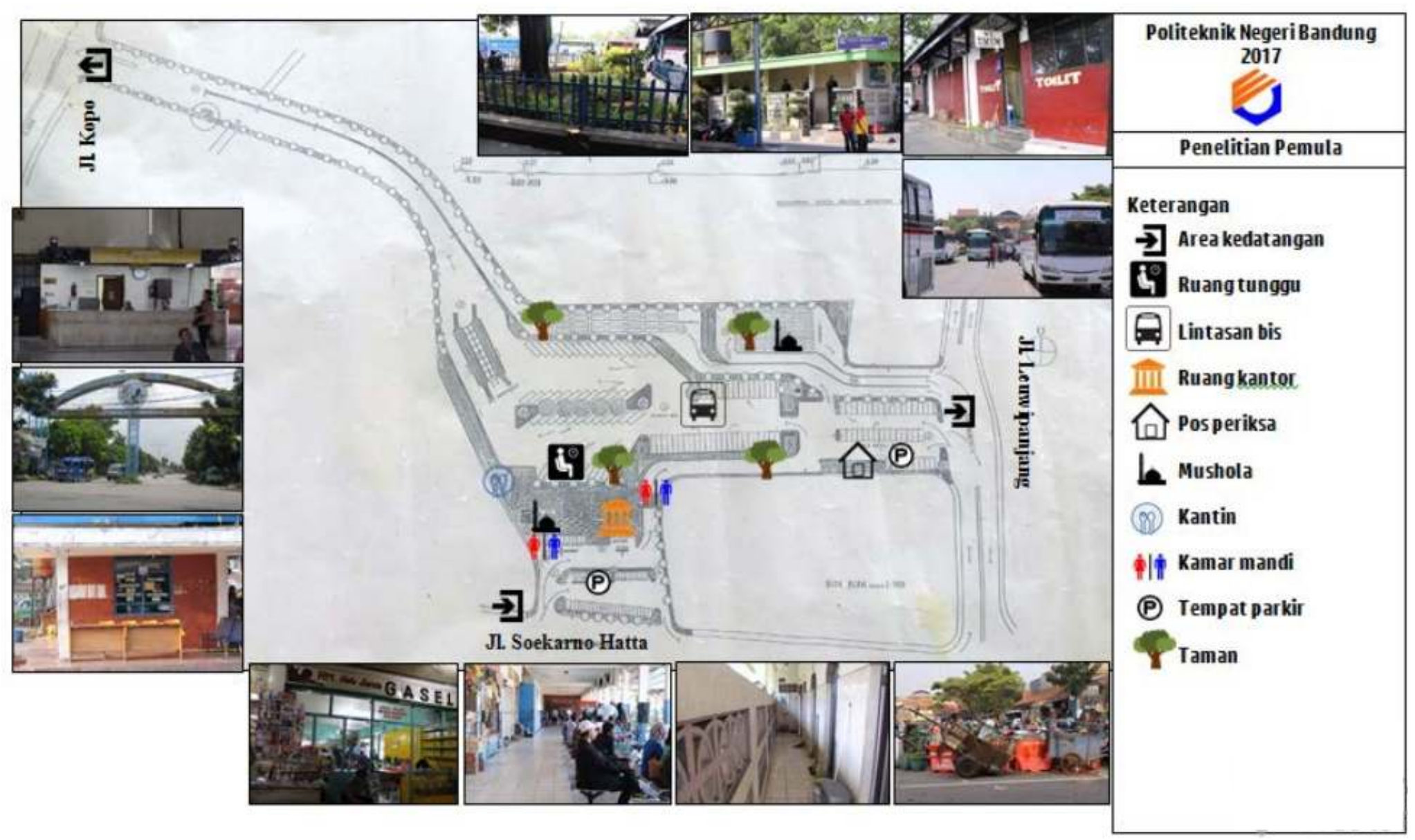

Gambar 3 Denah Lokasi Terminal Leuipanjang Kota Bandung

Sumber: Hasil olah data peneliti, 2017 


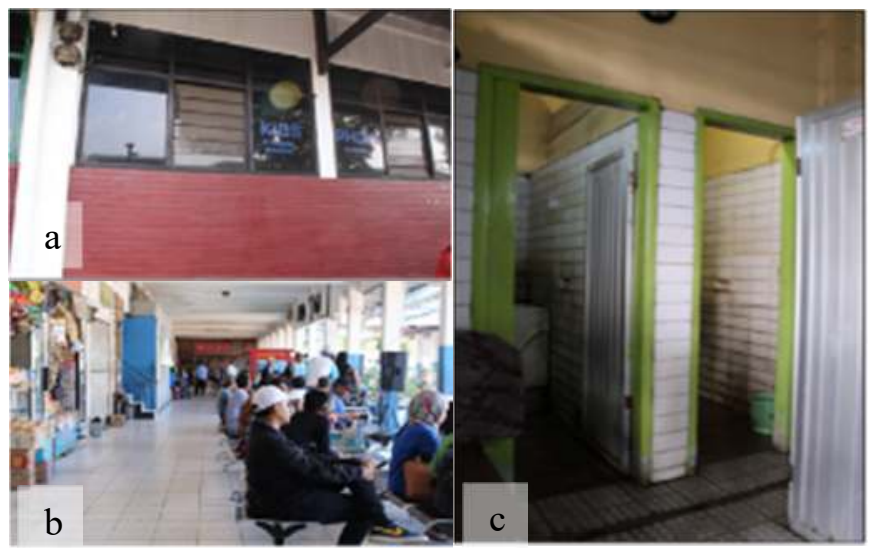

Gambar 4 Kegiatan Penumpang di Kawasan Terminal Leuwipanjang Kota Bandung Sumber: hasil dokumentasi peneliti, 2017

Standar kebersihan dan mutu ruangan berdasarkan hasil observasi pada gambar 4a dapat dilihat bahwa lantai gedung terminal berdebu, bernoda, buram, dan nat lantai yang kurang terawat. Pembersihan kaca merupakan kegiatan pemeliharaan yang dilakukan untuk nilai estetika. Namun jika dibiarkan, hal tersebut akan berdampak pada kesehatan orang-orang di sekitarnya. Standar kebersihan toilet dari beberapa aspek yakni pertama cermin berdasarkan hasil observasi dapat diamati bahwa kondisinya terlihat kusam seperti terlihat di gambar 4c. Disamping itu kondisi kran berkarat dan kusam. Beberapa kran yang mengalami kebocoran hanya ditambal dengan perlengkapan seadanya padahal sudah terlihat bahwa kerusakan yang dialami kran yakni rusak berat. Sedangkan taman terminal Leuwipanjang berada di sekitar area kedatangan AUP. Dari segi luasan, RTH kawasan terminal Leuwipanjang belum mencapai 30\% dari total luasan kawasan sekitar $3 \mathrm{Ha}$ (Undang-undang Nomor 26 Tahun 2007).

Aspek mutu ruangan selanjutnya yakni tata udara di lorong terminal Leuwipanjang. Berdasarkan persepsi penumpang dan hasil observasi, tata udara di lorong terminal terlihat pengap karena kurangnya sirkulasi udara. Disamping itu banyak rumah makan dan pedagang yang beraktivitas di dalam gedung terminal sehingga perlu dikaji lagi tata udara yang tepat. Dalam mengantisipasi hal tersebut, maka pihak pengelola perlu melakukan pemeriksaan secara berkala sistem tata udara.

Aspek mutu ruangan terakhir yakni tata udara di luar ruangan terminal yang dinilai sudah cukup baik. Hal tersebut terlihat dari adanya upaya penghijauan walaupun belum mencapai 30\% dari luasan area terminal Leuwipanjang. 


\section{Persepsi Penumpang Terhadap Pelayanan Fasilitas Fisik Terminal Penumpang Leuwipanjang}

Pelayanan adalah kegiatan atau rangkaian kegiatan dalam rangka pemenuhan kebutuhan pelayanan sesuai dengan peraturan perundang-undangan bagi setiap warga Negara dan penduduk atas barang, jasa, dan atau pelayanan administrasi yang disediakan oleh penyelenggara pelayanan publik (Peraturan Menteri Perhubungan No.40 Tahun 2015). Dalam menunjang pelayanan tersebut, dibutuhkan ketersediaan fasilitas fisik yang memadai. Hal tersebut sesuai dengan pendapat yang dikemukakan oleh Adisasmitha (2012), bahwa penyelenggaraan terminal harus meliputi fasilitas utama dan fasilitas pendukung.

Fasilitas utama terminal meliputi jalur pemberangkatan kendaraan umum, rute kedatangan kendaraan umum, tempat parkir kendaraan umum selama menunggu keberangkatan, termasuk di dalamnya terdapat tempat tunggu dan tempat istirahat kendaraan umum, bangunan kantor terminal, tempat tunggu penumpang dan atau pengantar, menara pengawas, loket penjualan karcis, rambu-rambu dan papan informasi (petunjuk jurusan, tarif, dan jadwal perjalanan), serta pelataran parkir kendaraan pengantar. Sedangkan fasilitas penunjang yakni kamar kecil atau toilet, kios atau kantin, mushola, ruang pengobatan P3K, ruang informasi dan pengaduan, telepon umum dan atau wartel, taman, serta tempat penitipan barang.

Terminal Penumpang Leuwipanjang merupakan terminal yang dikelola oleh UPTD Terminal dibawah Dinas Perhubungan Kota Bandung. Berdasarkan hal tersebut, standar pelayanan penyelenggaraan terminal penumpang yang sesuai menurut Peraturan Menteri No.40 Tahun 2015 secara lebih spesifik meliputi pelayanan keselamatan, keamanan, kehandalan dan keteraturan, kenyamanan, kemudahan dan keterjangkauan, serta kesetaraan. Berikut pada Gambar 5, hasil observasi memperlihatkan kondisi fasilitas keselamatan di kawasan terminal Leuwipanjang Kota Bandung.

Tiafahmi Angestiwi 58 Kajian Kondisi Fisik Terminal Leuwipanjang... 

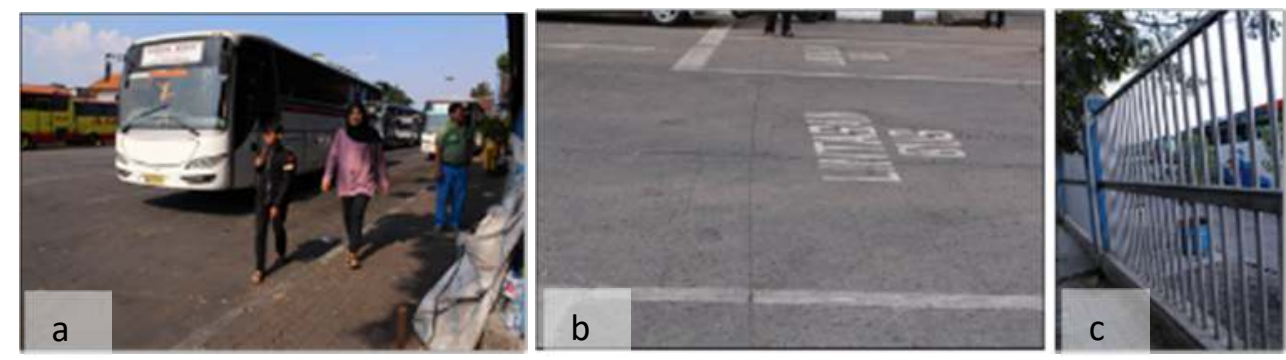

Gambar 5 Fasilitas Keselamatan di Kawasan Terminal Leuwipanjang Kota Bandung Sumber: Hasil Dokumentasi Peneliti, 2017

Keselamatan adalah keadaan terhindarnya setiap orang dari risiko kecelakaan selama berlalu lintas yang disebabkan oleh manusia, kendaraan, jalan, atau lingkungan (Undangundang No.22 Tahun 2009 tentang Lalu lintas dan Angkutan Jalan). Ketersediaan jalur pejalan kaki dan marka jalan dinilai sudah memadai berdasarkan persepsi penumpang. Jalur pejalan kaki adalah tempat setiap orang berjalan di ruang lalu lintas jalan (Undang-undang No.22 Tahun 2009 tentang lalu lintas dan angkutan jalan). Sedangkan marka jalan adalah suatu tanda yang berada di permukaan jalan atau di atas permukaan jalan yang meliputi peralatan atau tanda yang membentuk garis membujur, melintang, serong, serta lambing yang berfungsi mengarahkan arus lalu lintas dan membatasi daerah kepentingan lalu lintas

Aspek ketersediaan pelayanan keselamatan selanjutnya yakni jalur evakuasi, alat pemadam, pos kesehatan, dan info kesehatan secara keseluruhan dinilai cukup baik. Pos kesehatan terminal Leuwipanjang saat ini menggunakan fasilitas yang sama dengan ruang ibu menyusui. Sedangkan informasi keselamatan sebagai fasilitas penunjang pelayanan keselamatan dinilai kurang baik. Penumpang berpersepsi belum adanya signage terkait informasi petunjuk keselamatan, serta belum jelasnya arah sirkulasi jalur evakuasi dan titik kumpul yang mudah terlihat serta informatif. Berdasarkan hasil observasi, memang belum tersedia informasi yang yang menjelaskan dimana penumpang dapat berkegiatan secara aman ketika ada suatu hal terjadi. Sesuai dengan informasi pada undang-undang No.22 Tahun 2009 tentang lalu lintas dan angkutan Jalan bahwa informasi keselamatan digunakan agar terhindarnya setiap orang dari risiko kecelakaan selama berlalu lintas yang disebabkan oleh manusia, kendaraan, jalan, atau lingkungan

Secara menyeluruh pelayanan keamanan dinilai kurang baik. Keamanan adalah keadaan terbebasnya setiap orang, barang, atau kendaraan, dari gangguan perbuatan melawan hukum atau rasa takut dalam berlalu lintas (Undang-undang No.22 Tahun 2009 tentang Lalu lintas 
dan Angkutan Jalan). Fasilitas pencegah tindak kriminal tersedia di area masuk AUP. Fasilitas tersebut juga seharusnya juga dilengkapi di kawasan sekitar gedung terminal untuk mendukung terbebasnya dari gangguan hukum di seluruh kawasan terminal Leuwipanjang. Sedangkan ketersediaan stiker sulit dilihat dan tidak ditempet di tempat yang strategis. Sebaiknya pihak pengelola menempelkan stiker di area yang sering dilewati penumpang maupun ruang tunggu penumpang agar dapat diketahui dengan mudah. Terakhir yakni ketersediaan petugas berseragam perlu dipertimbangkan tidak hanyak weekday, tapi juga di akhir pekan.
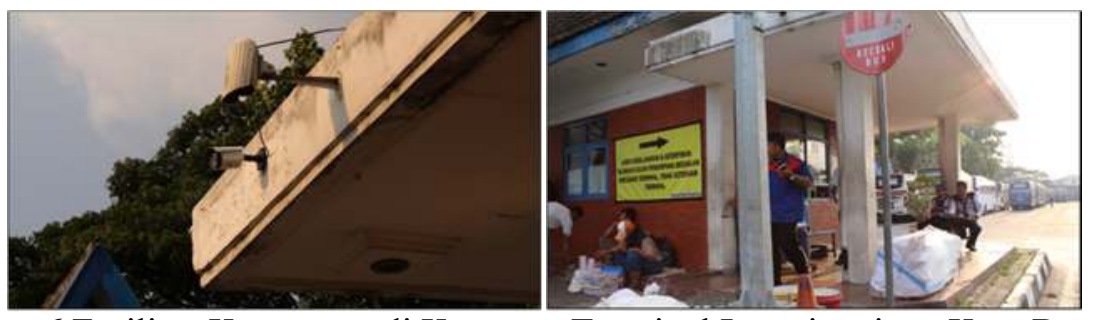

Gambar 6 Fasilitas Keamanan di Kawasan Terminal Leuwipanjang Kota Bandung Sumber: Hasil dokumentasi peneliti, 2017

Kehandalan adalah kemungkinan pelayanan terminal untuk tetap mampu berfungsi sesuai peruntukannya, kondisi, maupun waktu tanpa mengalami kegagalan (Campbell, 2011). Pada Gambar 7 dapat diamati hasil observasi mengenai fasilitas kehandalan.

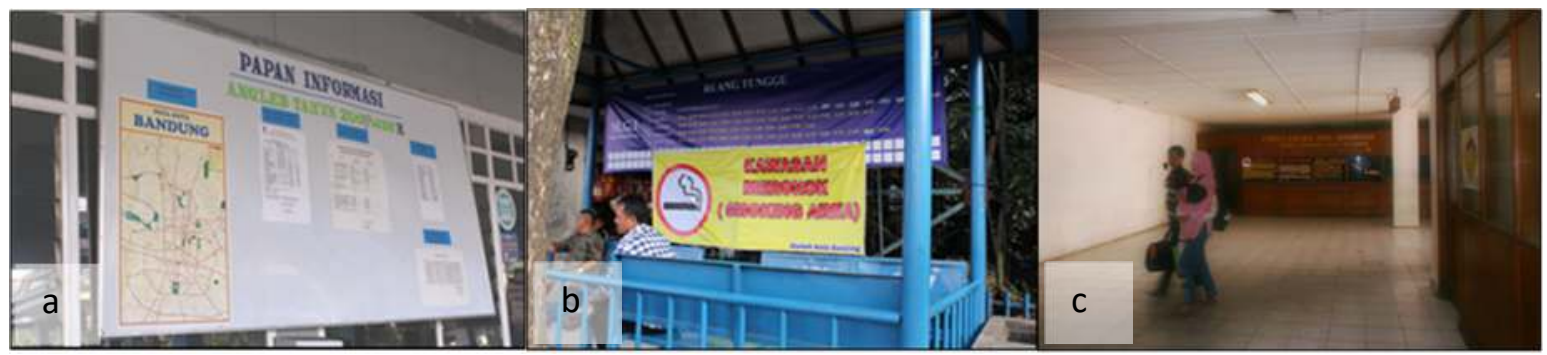

Gambar 7 Fasilitas Kehandalan di Kawasan Terminal Leuwipanjang Kota Bandung Sumber: Hasil dokumentasi peneliti, 2017

Berdasarkan persepsi penumpang dan hasil observasi, ketersediaan jadwal kendaraan dan kantor pengelola cukup baik. Pada papan informasi tertera jam memulai pelayanan dan jam pelayanan terakhir.Penumpang menilai adanya loket tiket yang tetap dan teratur. Sesuai Peraturan Menteri Perhubungan No.40 Tahun 2015 bahwa terminal tipe B tolak ukur indikator pelayanannya harus menyediakan loket penjualan tiket. Namun masih ada beberapa AUP yang menerapkan penjualan tiket tanpa melalui loket penjualan tiket di terminal. 
Pelayanan kenyamanan secara keseluruhan dinilai baik oleh penumpang. Hal tersebut sesuai dengan pendapat yang dikemukakan oleh Morlok (1991) bahwa fungsi dari terminal yang memadai mampu mendukung aktivitas penumpang dari waktu tiba, hingga waktu berangkat. Sedangkan dalam Undang-undang No.28 Tahun 2002, kenyamanan meliputi ruang gerak hubungan antar ruang.Hal tersebut dilihat dari tersedianya ruang tunggu, petugas kebersihan, tempat istirahat kendaraan, area merokok, jumlah dan luasan toilet, RTH, rumah makan, drainase serta penerangan. Sesuai dengan pendapat Morlok (1991) Pihak pengelola yakni UPTD terminal telah banyak meningkatkan fasilitas pendukung demi kenyamanan penumpang selama beraktivitas di kawasan terminal Leuwipanjang. Namun disisi lain, penumpang menilai kondisi toilet yang kotor sehingga berdampak pada bau yang ditimbulkan.

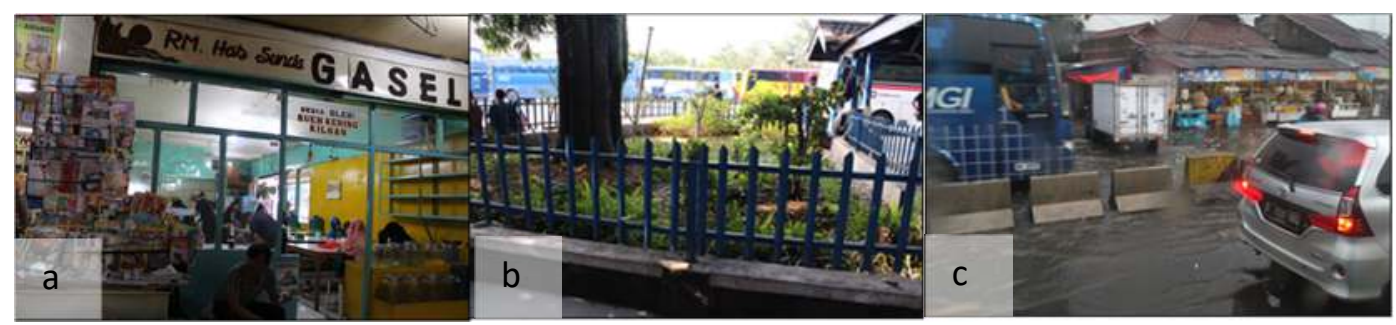

Gambar 8 Fasilitas Kenyamanan di Kawasan Terminal Leuwipanjang Kota Bandung Sumber: Hasil Dokumentasi Peneliti, 2017

Pelayanan kemudahan atau keterjangkauan terminal berdasarkan persepsi penumpang dan hasil observasi dinilai sudah memadai. Jalur kedatangan adalah pelataran di dalam terminal penumpang yang disediakan oleh pengelola bagi kendaraan umum untuk menurunkan penumpang (Peraturan Menteri Perhubungan No.132/2015). Sedangkan jalur keberangkatan adalah pelataran di dalam terminal penumpang yang disediakan oleh penyelenggara terminal bagi kendaraan umum untuk menaikkan penumpang. Jalur kedatangan dan keberangkatan dinilai sudah teratur dan tidak ada crossing antar satu AUP dengan AUP lainnya. Disisi lain tempat penitipan barang dan fasilitas pengisian baterai belum tersedia di kawasan terminal Leuwipanjang. Pelayanan kemudahan selanjutnya yakni ketersediaan tinggi platform yang belum sama dengan tinggi lantai bus. 


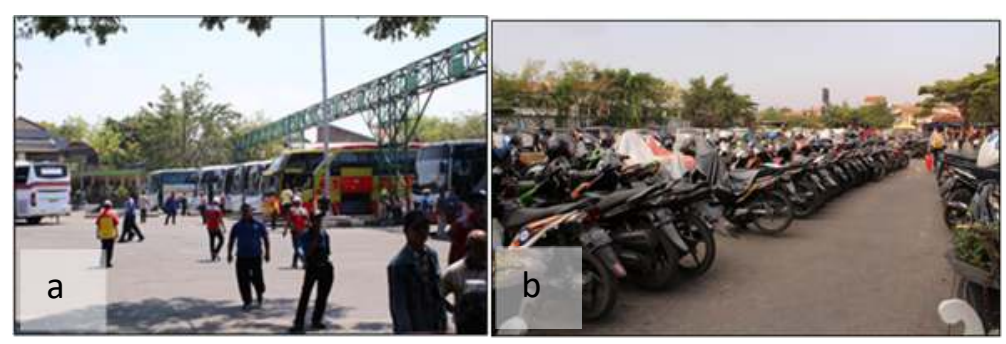

Gambar 9. Fasilitas Kemudahan/Keterjangkauan di Kawasan Terminal Leuwipanjang Kota Bandung Sumber: Hasil dokumentasi peneliti, 2017

Terakhir yakni lahan parkir yang dinilai belum memadai sebagai bentuk pelayanan kemudahan atau keterjangkauan. Parkir adalah keadaan kendaraan berhenti atau tidak bergerak untuk beberapa saat dan ditinggalkan pengemudinya (Undang-undang No.22 Tahun 2009 tentang lalu lintas dan angkutan jalan). Penumpang khususnya para pengantar baik kendaraan roda empat maupun roda dua berada di kawasan area masuk AUP sehingga suasana kendaraan menjadi tidak terkendali karena pengantar dan penjemputan penumpang hilir mudik di area masuk AUP.

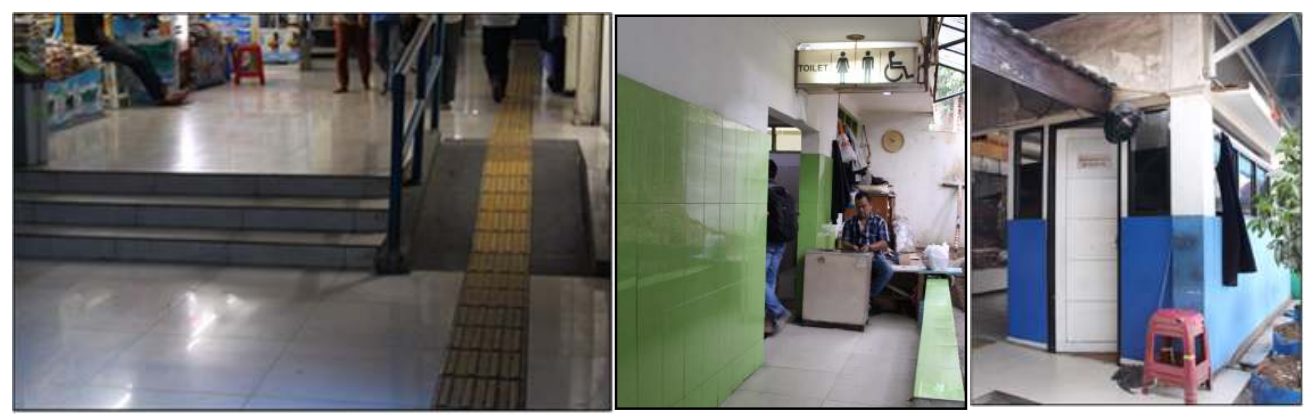

Gambar 10. Fasilitas Kemudahan/Keterjangkauan di Kawasan Terminal Leuwipanjang Kota Bandung Sumber: Hasil dokumentasi peneliti, 2017

Dalam Peraturan Menteri Perhubungan No.132 Tahun 2015 bahwa fasilitas difable dan ibu hamil atau menyusui termasuk fasilitas penunjang, yakni fasilitas pilihan yang menunjang penyelenggaraan dan pengoperasian terminal. Berdasarkan persepsi penumpang dan hasil observasi pelayanan kesetaraan dinilai cukup baik. Hal tersebut dikarenakan belum terdapat ramp portable dengan standar kemiringan maksimum $20^{\circ}$ untuk penyambung dari platform ke kendaraan. Namun di lorong terminal sudah tersedia akses jalan yang memfasilitasi kaum difabel. Disamping itu juga tersedia toilet bagi pengguna difabel. 
Jurnal Planologi Vol. 15, No. 1, April 2018

Available : http://jurnal.unissula.ac.id/index.php/psa

\section{KESIMPULAN DAN SARAN \\ Kesimpulan}

Berdasarkan hasil analisis data yang diperoleh, penulis menarik beberapa kesimpulan.

Adapun kesimpulan-kesimpulan tersebut adalah sebagai berikut:

1. Persepsi penumpang terhadap hasil pemeliharaan aspek kondisi fisik terminal penumpang Leuwipanjang secara keseluruhan dapat dinilai cukup baik. Menurut persepsi penumpang terhadap standar kebersihan fisik terminal Leuwipanjang masih terlihat plafon yang ada bekas bocoran dan masih ada debu di sudut-sudutnya. Kaca dan lantai yang berdebu. Disamping itu ruang toilet masih kotor dengan lantai di sekitarnya basah, bahkan keset di kamar mandi menggunakan kardus bekas. Lantai aspal di area keluar masuk AUP dibiarkan daun-daunan berserakan. Mutu ruangan terminal Leuwipanjang yang mencakup udara lorong dan luar luar. Udara di lorong terminal masih terlihat pengap karena sirkulasi udara yang kurang baik. Banyaknya kegiatan meliputi pedagang oleh-oleh lalu kantin, masjid dan toilet sehingga membutuhkan sirkulasi yang baik. Selain itu sirkulasi udara luar terlihat adanya upaya penghijauan namun belum mencapai $30 \%$ dari luasan terminal.

2. Persepsi penumpang terhadap ketersediaan fasilitas fisik terminal penumpang Leuwipanjang secara keseluruhan dapat dinilai cukup baik. Ketersediaan kondisi fisik yang mendukung pelayanan keselamatan belum memadai karena belum tersedianya jalur evakuasi dan titik kumpul yang dapat digunakan penumpang saat terjadi bencana di kawasan Terminal Leuwipanjang. Ketersediaan kondisi fisik yang mendukung pelayanan keamanan tidak memadai. Penyediaan kamera hanya dipertuntukkan di lokasi keluar masuk AUP. Ketersediaan kondisi fisik yang mendukung pelayanan keandalan dan keteraturan dinilai belum memadai. Loket tiket belum digunakan baik untuk perjalanan antar kota antar provinsi maupun antar kota dalam provinsi. Sedangkan ketersediaan kondisi fisik yang mendukung pelayanan kenyamanan saat ini sudah memadai. Ketersediaan ruang tunggu, fasilitas ibadah, dan area merokok sudah mengalami peningkatan dari segi kapasitas maupun fasilitas pendukungnya. Namun kondisi RTH, rumah makan, toilet dan drainase harus menjadi perhatian pihak pengelola untuk menyediakan fasilitas yang layak fungsi. Sedangkan ketersediaan kondisi fisik yang mendukung pelayanan kemudahan atau keterjangkauan sudah memadai. Jalur 
keberangkatan dan jalur kedatangan sudah teratur dan tidak ada crossing saat menaikkan dan menurunkan penumpang. Namun masih belum tersedia fasilitas pengisian baterai di spot-spot tertentu. Terakhir yakni ketersediaan kondisi fisik yang mendukung pelayanan kesetaraan sudah memadai. Sudah ada fasilitas toilet difable dan ruang bagi ibu menyusui. Namun belum tersedia ramp portable dengan kemiringan maksimum $20^{0}$ untuk penyambung platform ke kendaraan.

\section{Saran}

Berdasarkan kesimpulan tersebut, maka alternatif saran yang dapat dilakukan oleh pihak pengelola yakni Dinas Perhubungan Kota Bandung melalui UPTD Terminal adalah:

1. Dinas Perhubungan Kota Bandung melalui UPTD Terminal hendaknya memperhatikan standar kebersihan fisik terminal dalam mendukung fungsi sebagai terminal penumpang AKAP (Angkutan Kota Antar Provinsi) dan AKDP (Angkutan Kota Dalam Provinsi). Alternatif solusi dari permasalahan kebersihan kondisi fisik terminal dan mutu ruangan yakni dengan membuat jadwal pemeliharaan baik harian, mingguan, bulanan, dan tahunan untuk kegiatan pembersihan dan pemeriksaan secara rutin sebagai bentuk preventive maintenance.

2. Ketidaktersediaan beberapa pendukung kondisi fisik terminal Leuwipanjang dalam melayani penumpang dapat dilakukan dengan monitoring selama berlangsungya pelayanan terminal Leuwipanjang. Kemudian untuk fasilitas pendukung yang belum tersedia meliputi jalur evakuasi, titik kumpul, dan fasilitas pengisian baterai dapat mulai direncanakan untuk pengadaannya. Disamping itu RTH perlu menjadi perhatian khusus karena terutama pihak pengelola perlu memperhatikan sirkulasi udara yang baik baik di dalam gedung terminal maupun di luar terminal agar penumpang mendapatkan udara sehat saat berada di terminal Leuwipanjang.

\section{DAFTAR PUSTAKA}

Abubakar. (1996) Menuju Lalu-Lintas dan Angkutan Jalan yang Tertib. Jakarta: Direktorat Jenderal Perhubungan Darat

Adisasmita, Sakti. (2012). Perencanaan Infrastruktur Transportasi Wilayah. Makasar: Graha Ilmu 
Angestiwi, Tiafahmi. (2013) Kinerja Terminal Leuwipanjang Terhadap Pergerakan Kota Bandung. Thesis di Universitas Diponegoro

Anonim. (2007). Undang-undang Nomor 26 Tahun 2007 tentang Penataan Ruang.

Anonim, (2008). Peraturan Menteri Pekerjaan Umum Nomor 24 Tahun 2008 tentang Pedoman Pemeliharaan dan Perawatan Bangunan Gedung

Anonim. (2009). Undang-undang Nomor 22 Tahun 2009 tentang Lalu Lintas dan Angkutan Jalan.

Anonim. (2015). Peraturan Menteri Perhubungan Nomor 132 Tahun 2015 tentang Penyelenggaraan Terminal Penumpang Angkutan Jalan.

Anonim. (2015). Peraturan Menteri Perhubungan RI Nomor 40 Tahun 2015 tentang Standar Pelayanan Penyelenggaraan Terminal Penumpang Angkutan Jalan.

Blow, Christoper. (2005). Terminals and Modal Interchanges. Oxford:Architectural Press

Campbell, John. (2011). Asset Management Excellence. United State: CRC Press

Hariyono, Arik. (2007). Prinsip dan Teknik Manajemen Kekayanaan Negara. Jakarta: Departemen Keuangan Republik Indonesia Badan Pendidikan dan Pelatihan Keuangan Pusdiklat Keuangan Umum

Harvey dan Swith. (1997). Modelling the Impact of Customer-Employee Relationship, University Of Central England, Birmingham

Morlok, Edward. (1991). Pengantar Teknik dan Perencanaan Transportasi..Jakarta: Erlangga Sugiama, Gima. (2008). Metode Riset. Bandung:Guardaya Intimarta

Seshadhri, Gopikrishnan Paul, Virendra Kumar. (2017). User requirement related performance attributes for government residential buildings. Journal of Facilities Management, Vol.15 Nomor: 4 hal.409-422 